\title{
Bariatric surgery focused issue
}

Obesity is now considered to be a global endemic with its prevalence having nearly tripled worldwide between 1975 and 2016 (1). In 2016, over 1.9 billion adults aged 18 years and over (39\% men and $10 \%$ women) were overweight (1). Of these $>650$ million adults, i.e., approximately $11 \%$ men and $15 \%$ women were obese (1). In 2010, overweight and obesity were estimated to cause 3.4 million deaths, $4 \%$ of years of life lost, and $4 \%$ of disability-adjusted life-years (DALYs) worldwide (2). Furthermore, raised body mass index (BMI) is a major risk factor for noncommunicable diseases such as cardiovascular disease (CVD) (particularly heart disease and stroke); diabetes; musculoskeletal disorders (mainly osteoarthritis); and numerous types of cancers (i.e., endometrial, cervical, breast, ovarian, prostate, liver, gallbladder, thyroid, kidney, colon and leukemia) (3). As obesity prevalence continues to increase, so too will the associated disease burden and health care costs, posing a crippling financial burden to any health care system. Utilization of bariatric surgical procedures have been proposed as cost effective and efficacious strategies to manage obesity-related chronic disease and metabolic conditions in moderately to severely obese people (4-7). For this focused issue on bariatric surgery, a number of bariatric physicians, surgeons, dieticians, psychologists and epidemiologists have come together to address the impact of various bariatric procedures, not just on short and long term weight loss, but in terms of longevity, quality of life, as well as the impact on various co-morbidities and cancers. However, as with all surgical procedures-especially those in a high-risk bariatric population-bariatric procedures are not undertaken without a degree of risk of complications that may lead to further burden on the health system and diminished postoperative quality of life.

Dr. Caltabiano from Cairns, Australia undertook an online survey to assess obesity health-related quality of life and body image satisfaction in a group of individuals having undergone bariatric surgery. Her conclusions suggested that body image concerns were more important predictors for well-being post bariatric surgery than weight loss. It is therefore essential that the importance of body image assessment pre- and post-bariatric surgery should be addressed as a part of psychological assessment and support.

Dr. El-Beheiry and colleagues from Manitoba, Canada undertook a survey of primary care physicians (PCPs) referral to assess their knowledge and perception of a provincial bariatric surgery program in Manitoba. The authors found knowledge deficit by the PCPs in discussing the role of bariatric surgery and therefore extremely small number of patients were referred for these lifesaving surgeries. They feel continuing medical education activities targeted to PCPs most likely will improve the knowledge deficit.

Dr. Furbetta and colleagues from Pisa, Italy have provided us a detail history and impact of laparoscopic adjustable gastric banding (LAGB) on weight loss surgery. Although the LAGB has seen a relative decline in utilization compared to other procedures, it remains widely practiced by the surgical community because of its simplicity and reversibility, and has demonstrated a reasonable success rate over a prolong period of time and low complication sequalae. Furthermore, as it does not have any significant impact on the anatomy of the stomach, further resectional surgeries such as laparoscopic vertical sleeve gastrectomy (LVSG) or laparoscopic Roux-en-Y gastric bypass (LRYGB) can be undertaken if required at a later date.

Drs. Khaitan and Shea from Ohio, USA have provided a review on the most popular and contemporary laparoscopic bariatric procedure, the LVSG. According to these authors, short term outcomes have certainly been promising in terms of weight loss and resolution of comorbid conditions. Long term outcomes are still evolving, but do demonstrate durable weight loss for a significant number of patients. There are certain concerns with the LVSG in the long term which includes the development or worsening of gastroesophageal reflux disease (GERD) and weight regain. Randomized controlled trials comparing LVSG and laparoscopic Roux-en-Y gastric bypass with five-year comparison data show equivalent results for both of these procedures with very low complication rates encouraging more surgeons to adopt LVSG as the procedure of choice because of its technical simplicity.

Drs. Aly and Mori from Melbourne, Australia, have provided an illuminating review on the role LRYGB in the Super Obese $\left(\mathrm{BMI}>50 \mathrm{~kg} / \mathrm{m}^{2}\right)$ with its technical challenges. According to these authors there remain many concerns regarding the safety and efficacy of LRYGB in these patients. They have therefore suggested two step approach such as LVSG as the first step followed by LRYGB to achieve a better success and mitigate the risk of complications with a more complicated procedure in this population of patients.

Dr. Aleman and colleagues, from Florida, USA have examined the controversies surrounding a more recently introduced bariatric procedure, the one-anastomosis gastric bypass (OAGB). The authors believe that based on the available evidence, this technique poses a challenge to LRYGB in its establishment as a standard of care procedure. The anatomical configuration following surgery especially the afferent limb length, the metabolic implications of its hypo-absorptive nature, and lack of long-term data needs further scrutiny. Hence, prospective studies with long-term follow-up ( $>5$ years) can bypass these concerns and allow the progression of the clinical practice of OAGB.

Dr. Gollisch and Raddatz from Gottingen, Germany have tackled the topic of endoscopic intragastric balloon which is ideally utilized for overweight and moderately obese patient with a limited range of BMI (e.g., 27 to $37 \mathrm{~kg} / \mathrm{m}^{2}$ ). This 
procedure is offered to individuals who do not desire any invasive surgical procedure but are keen to lose weight, or as a bridging procedure before undergoing some form of definite bariatric surgical procedure. According to the authors, as a complement to lifestyle interventions the intragastric balloon may have its place as it facilitates initial weight loss and thus may increase the patient's motivation to continue lifestyle efforts.

Osland and colleagues from Brisbane, Australia, have provided a practical review on the pivotal role dietitians have in the identification, prevention and management of micronutrient vulnerabilities in bariatric patients. They highlight the nutritional considerations required in the management of post-bariatric surgery pregnancy, and the importance of lifelong nutritional care in post-bariatric patients to prevent long term nutritional complications.

Drs. Gu and Vergis from Saskatoon, Canada, have introduced the subject of LVSG and LRYGB and its impact on type 2 diabetes mellitus (T2DM). The authors feel that both procedures are quite effective in improving this condition especially when compared to conventional medical treatment. A number of randomized controlled trials with five-year data, however, have shown a slightly better outcome of LRYGB over LVSG not just in terms of weight loss but also for resolution of a number of comorbidities such as T2DM.

Dr. Ashrafi and colleagues from Brisbane, Australia have provided an insight into the role of bariatric procedures and their influence on GERD. The authors feel that different bariatric procedures have unpredictable effects on an established GERD and may even cause de novo GERD. It is therefore important that preoperative investigations such as 24-hour ambulatory pH study and high-resolution manometry be performed in all these patients to select the most suitable bariatric procedure for its long-term success.

Dr. English and colleagues from Tennessee, USA have reviewed the literature on CVD risk reduction following bariatric surgical procedures. The literature has shown that a substantial and sustained decrease in body weight after metabolic and bariatric surgery is associated with a significant reduction of CVD risk factors such as T2DM, HTN and hypertriglyceridemia, however, this has not been seen in nonsurgical weight loss trials. Therefore, metabolic and bariatric procedures demonstrate significant CVD risk reduction and mortality reduction, while often completely eliminating numerous comorbidities and improving quality of life. The authors have concluded that duodenal switch appears to show better long-term reduction in CVD risk factors followed by LRYGB, LVSG and LAGB.

Drs. Bruno and Berger from Ohio, USA have provided a succinct summary of the latest literature addressing the potential cancer prevention effects of bariatric surgery. According to the authors although the role of bariatric surgery and cancer risk reduction is controversial, most trials indicate that bariatric surgery reduces overall risk of cancer development predominantly in women compared to men and most significantly for breast and endometrial cancer. There is also some controversy regarding increase risk of colorectal cancer following bariatric surgery and presently it is undergoing intense scrutiny. The authors feel that it is entirely possible that obesity-related cancer may be impacted by epigenetic determination, and that bariatric surgery during middle-age may have little impact in preventing cancer. Longitudinal studies of various bariatric procedures with at least 10-year follow-up may provide us a clearer picture in the future.

Lastly, I would like to thank all the authors who participated in this epic effort to produce this very comprehensive and focused issue on bariatric surgery. I am honored and humbled by the participation of these international authorities on their subject matter and enjoyed working side by side with these wonderful people.

\section{Acknowledgments}

Funding: None.

\section{Footnote}

Provenance and Peer Review: This article was commissioned by the editorial office, Annals of Translational Medicine for the focused issue "Bariatric surgery". The article did not undergo external peer review.

Conflicts of Interest: The focused issue "Bariatric Surgery" was commissioned by the editorial office without any funding or sponsorship. MAM served as the unpaid Guest Editor of the focused issue.

Ethical Statement: The author is accountable for all aspects of the work in ensuring that questions related to the accuracy or integrity of any part of the work are appropriately investigated and resolved. 
Open Access Statement: This is an Open Access article distributed in accordance with the Creative Commons Attribution-NonCommercialNoDerivs 4.0 International License (CC BY-NC-ND 4.0), which permits the non-commercial replication and distribution of the article with the strict proviso that no changes or edits are made and the original work is properly cited (including links to both the formal publication through the relevant DOI and the license). See: https://creativecommons.org/licenses/by-nc-nd/4.0/.

\section{References}

1. World Health Organization. Obesity and Overweight. Available online: https://www.who.int/en/news-room/fact-sheets/detail/ obesity-and-overweight. Accessed January 27, 2020.

2. Lim SS, Vos T, Flaxman AD, et al. A comparative risk assessment of burden of disease and injury attributable to 67 risk factors and risk factor clusters in 21 regions, 1990-2010: a systematic analysis for the Global Burden of Disease Study 2010. Lancet 2012;380:2224-60.

3. Bhaskaran K, Douglas I, Forbes H, et al. Body-mass index and risk of 22 specific cancers: a population-based cohort study of 5.24 million UK adults. Lancet 2014;384:755-65.

4. Colquitt JL, Pickett K, Loveman E, et al. Surgery for weight loss in adults. Cochrane Database Syst Rev 2014;(8):CD003641.

5. Picot J, Jones J, Colquitt JL, et al. The clinical effectiveness and cost-effectiveness of bariatric (weight loss) surgery for obesity: a systematic review and economic evaluation. Health Technol Assess 2009;13:1-190, 215-357, iii-iv.

6. Borisenko O, Adam D, Funch-Jensen P, et al. Bariatric Surgery can Lead to Net Cost Savings to Health Care Systems: Results from a Comprehensive European Decision Analytic Model. Obes Surg 2015;25:1559-68.

7. Suter M, Donadini A, Romy S, et al. Laparoscopic Roux-en-Y gastric bypass: significant long-term weight loss, improvement of obesity-related comorbidities and quality of life. Ann Surg 2011;254:267-73.

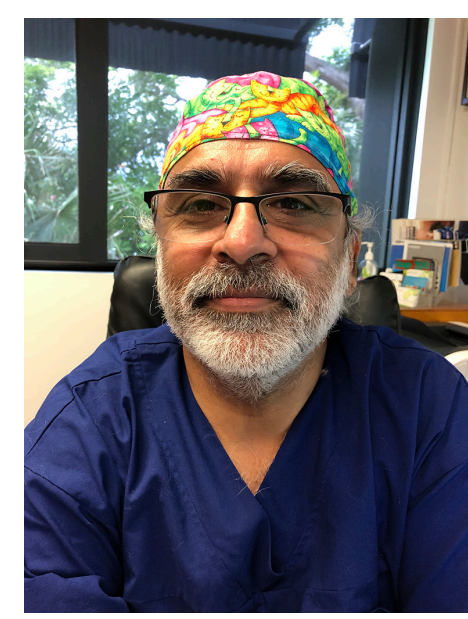

Muhammed Ashraf Memon

\begin{abstract}
Muhammed Ashraf Memon ${ }^{1,2,3,4,5}$, MBBS, MA, DCH, FACS, FRACS, FRCSI, FRCSEd, FRCSEng

${ }^{1}$ Mayne Medical School, School of Medicine, University of Queensland, Brisbane, Queensland, Australia; ${ }^{2}$ School of Agricultural, Computational and Environmental Sciences, International Centre for Applied Climate Sciences and Centre for Health Sciences Research, University of Southern Queensland, Toowoomba, Queensland, Australia; ${ }^{3}$ Sunnybank Obesity Centre South \& East Queensland Surgery (SEQS), Sunnybank, Queensland, Australia $;{ }^{4}$ Faculty of Health Sciences and Medicine, Bond University, Gold Coast, Queensland, Australia; ${ }^{5}$ Faculty of Health and Social Science, Bolton University, Bolton, Lancashire, UK. (Email:mmemon@yahoo.com) Submitted Feb 01, 2020. Accepted for publication Feb 20, 2020. doi: $10.21037 / \mathrm{atm} .2020 .02 .55$

View this article at: http://dx.doi.org/10.21037/atm.2020.02.55
\end{abstract}

Cite this article as: Memon MA. Bariatric surgery focused issue. Ann Transl Med 2020;8(Suppl 1):S1. doi: 10.21037/ atm.2020.02.55 